\title{
UAV BASED MULTI SEASONAL DECIDUOUS TREE SPECIES ANALYSIS IN THE HAINICH NATIONAL PARK USING MULTI TEMPORAL AND POINT CLOUD CURVATURE FEATURES
}

\author{
S. Hese ${ }^{1 *}$, C. Thiel $^{2}$, A. Henkel ${ }^{3}$ \\ ${ }^{1}$ Friedrich-Schiller-Universität Jena, Institut für Geographie, Lehrstuhl für Fernerkundung, 07743 Jena, Germany - \\ soeren.hese@uni-jena.de \\ ${ }^{2}$ Deutsches Zentrum für Luft- und Raumfahrt (DLR), Institut für Datenwissenschaften, Mälzerstraße 3, 07745 Jena, Germany - \\ christian.thiel@dlr.de \\ ${ }^{3}$ Nationalpark Verwaltung Hainich, Bei der Marktkirche 9, 99947 Bad Langensalza, Germany - andreas.henkel@nnl.thüringen.de
}

KEY WORDS: Tree species, Crown Surface, Gaussian Curvature, Roughness, Point Cloud, UAV, Multi Seasonal

\begin{abstract}
:
Low cost UAV systems are a flexible and mobile platform for very detailed spatial high-resolution point cloud and surface height mapping projects. This study investigates the potential of the DJI Phantom 4 Pro 3D point clouds and derived crown surface height information in combination with RGB spectral information for mapping of deciduous tree species in the Hainich national park area. RGB image data was captured in August, early October and November 2018 to create a multi seasonal spectral dataset for a 100 ha test area. The flight campaigns were controlled from the Hainich flux tower platform in $40 \mathrm{~m}$ height owned and operated by University of Göttingen in the central part of the park area. Absolut georeferencing accuracy of the datasets was improved using 7 DGPS measured control points within the stand structure on small forest clearings. Image files and ground control points were processed to a dense point cloud model with 2.6 billion points (approximately 200k points per tree crown object) using the Agisoft Metashape cluster processing environment. Additionally, a digital surface model and a true ortho image mosaic with $3 \mathrm{~cm}$ spatial resolution was generated. For the differentiation of deciduous tree species, a reference data set with coordinates for the tree species Fagus sylvatica (beech), Fraxinus excelsior (ash), Acer pseudoplatanus (sycamore maple), Carpinus betulus (hornbeam) and dead trees and early defoliated trees was defined. The study site is however dominated by Fagus sylvatica and Fraxinus excelsior. We studied two different groups of features: tree crown surface height variability parameters using point cloud densities, point cloud height variance, local standard deviation of gaussian curvature, standard deviation of local point cloud roughness and multi temporal normalised spectral features using multi seasonal uncalibrated UAV RGB data. Analysis of feature separability showed that very high-resolution point cloud surface curvature properties with small neighbourhood radii can differentiate some tree species types but we also found multitemporal spectral ratios based on RGB data to be very successful in differentiating the main tree species.

Results of this work show that super fine very dense point cloud models and derived roughness measures of mixed forest stand surfaces hold valuable information for deciduous species discrimination and will likely also be very useful for morphological analysis of tree crown types.
\end{abstract}

\section{INTRODUCTION}

Small Off The Shelf (OTS) quadro copter systems provide a very cost effective, highly flexible, mobile platform for high resolution point cloud mapping. Various studies showed the full potential of these small and flexible platforms (Mlambo et al. 2017). An overview is also given in Colomina and Molina (2014). Especially in very complex 3D environments the automatic obstacle avoidance, low copter weight, long flight times and precise manoeuvring are important advantages of small OTS systems in comparison with larger octocopter systems. Especially for the mapping of 2.5D structures - mapping a continuous height surface of a stand and not volume 3D structures - the airborne Lidar and the image-based UAV Structure from Motion (SfM) approach create comparable surface representation results (Thiel and Schmullius 2016). Since the development of very fast Graphic Processing Units (GPU) with multiple processing cores the computing times for image matching have decreased considerably making projects with hundreds to thousands of full-resolution 12-24 megapixel image files possible now. Studies in the past have shown that this is possible even with un-georeferenced images from various sources and with varying image quality (Snavely, Seitz and Szeliski 2008). Photogrammetric grade cameras have been used together with GPS and IMU (Inertial Measurement Unit) data to extract camera position and orientation data and various applications with very high-resolution airborne data have been published (Ofner et al. 2006). With SfM approaches the 3D modelling is done directly based on multiple overlapping images and position/orientation data is not necessarily needed. These concepts do not require any orientation information although orientation and GPS information is an advantage for fast data processing. The applied concepts usually use features that are independent of dissimilarities between overlapping images. Namely the SIFT and the SURF operator (Bay et al. 2008, Lingua, Marenchino \& Nex 2009, Lowe 2004) play a critical role for the successful introduction in various 3D point cloud mapping software solutions. First publications go back into the 1990s and earlier (Lowe 1999 and Ulman 1979). The SfM

\footnotetext{
* Corresponding author
} 
concept is exemplary summarized e.g. in Carrivick et al. (2016). Detailed summary of the overall concept is also available in Smith et al. (2015). While the concept is very flexible it inherits some problems when point clouds are analysed and compared to ALS/TLS (Airborne/Terrestrial Laser Scanning) datasets. The density of the point cloud is not necessarily proportional linked to the surface density of a complex object surface. It is therefore difficult to compare the ALS/TLS point clouds of deciduous and coniferous trees with those coming from SfM concepts.

This study examines the potential of very small UAV-Systems (small sized Unmanned Aerial Vehicles below $5 \mathrm{~kg}$ ) for detailed multi-seasonal tree canopy mapping using both spectral features and point cloud height-based features of a 100 ha area in the Hainich national park. While spatial very high-resolution analysis of tree species types has been conducted long before e.g. in Hirschmugl et al. (2007) there is not much research on point cloud densities and variabilities of the individual crown surface roughness and curvature of crown surface subsets for larger stands available so far. This is mainly due to the lack of availability of very dense point clouds with full modelling of the crown morphology for larger areas and continuous forest stand structures in the $\mathrm{cm}$ resolution range. This data could be very important for the validation of components of forest growth models (Pretzsch, Forrester and Rötzer 2015) or for measuring plant interception volume. A lot of work has been done investigating Laser scanning data for species differentiation (Hollaus et al. 2009, Korpela et al. 2010, Kim et al. 2009, Orka et al. 2009, Othmani et al. 2011, Person et al. 2004, Reitberger et al. 2006 and Brandberg 2007).

Gap fraction and tree roughness were investigated with TLS data by Antonarakis et al. (2010) and surface roughness on stand level scale was e.g. analysed with TLS/ALS data by Weligepolage, Gieske and $\mathrm{Su}$ (2012). Spatial very highresolution TLS data f.e. was used by Othmani et al. (2013) to classify tree species by 3D bark texture. Published work by Pretzsch (2014) showed that in mixed stands the crown projection area of beech trees is less circular and crown eccentricity is increased. Fractal dimension of the mixed crown surface area and leaf area is changed "from lower space filling (Euclidian scaling) towards higher space filling of the crown volume (fractal scaling)" (Pretzsch 2014). In mixed stands this could modify the crown surface roughness of different tree species. Crown morphology and canopy structure as a result of environment and its impact on growth of the various species are at the same time the important driver and the product of stand dynamics (Pretzsch 2014). Crown overlap in multiple layers in mixed stands clearly complicates any analysis of crown surface parameters.

\section{DATA AND STUDY SITE}

The Hainich national park ("Nationalpark Hainich") was founded December 31, 1997 and is the only national park in Thuringia. Main objective is the beech forest and fauna protection and the restoration of a primordial status. The park area covers $75 \mathrm{~km}^{2}$ in the western German state Thuringia. The national park is a part of the largest deciduous forest region $\left(160 \mathrm{~km}^{2}\right)$ in Germany broadly named "Hainich". The study site is situated in the central part of the national park and forms a rectangular 100 ha shape surrounding the flux measurement tower of the University of Göttingen (Figure 1). The forest is dominated by beech trees (Fagus sylvatica), ash trees (Fraxinus Excelsior) and sycamore maple (Acer Pseudoplatanus), other tree species are field maple, hornbeam
(Carpinus Betulus), wych elm (Ulmus Glabra), lime trees, Norway maple, cherry and oak. The forest is completely unmanaged and includes stands of flowers and fungi and various animal species (wildcats, various species of bats, wood peckers and wood beetles and also wild pigs).

For this work the DJI Phantom 4 Pro (Table 1) was used, flight altitude above crown level was $100 \mathrm{~m}, \mathrm{X} / \mathrm{Y}$-overlap $74 \%$, resulting spatial resolution was $0.03 \mathrm{~m}(3 \mathrm{~cm})$.

\begin{tabular}{|l|c|c|c|}
\hline & $\mathbf{3 1 . 8 . 2 0 1 8}$ & $\mathbf{1 5 . 1 0 . 2 0 1 8}$ & $\mathbf{7 . 1 1 . 2 0 1 8}$ \\
\hline No. of images & 625 & 624 & 612 \\
\hline Resolution m & 0.03 & 0.03 & 0.03 \\
\hline Altitude in m & \multicolumn{3}{|c|}{$100 \mathrm{~m}$ (relative to start altitude) } \\
\hline $\begin{array}{l}\text { Camera- } \\
\text { system }\end{array}$ & \multicolumn{3}{|c|}{$\begin{array}{c}\text { Phantom 4 Pro, DJI FC6310, full frame } \\
\text { equivalent: 24mm, f2.8, 20MP, 1-inch DJI } \\
\text { FC6310 RGB (Bayer) sensor. }\end{array}$} \\
\hline Overlap in \% & \multicolumn{3}{|c|}{$74 / 74$} \\
\hline DGPS points & 7 & 0 & 0 \\
\hline Exposure (fix) & $1 / 400 \mathrm{~s}$ f5.6 & $1 / 400 \mathrm{~s}$ f4 & $1 / 500$ s f5 \\
\hline ISO & 400 & 200 & 400 \\
\hline Flight time & 31.8 .2018 & 15.10 .2018 & 7.11 .2018 \\
& $12: 04-12: 51$ & $13: 49-14: 31$ & $12: 23-13: 04$ \\
\hline File format & \multicolumn{2}{|c|}{ JPEG with EXIF GPS location \& } \\
& barometric height \& WGS84 altitude \\
\hline
\end{tabular}

Table 1: Hainich flight plan information for the August, September and November flights over the "Huss"-area.

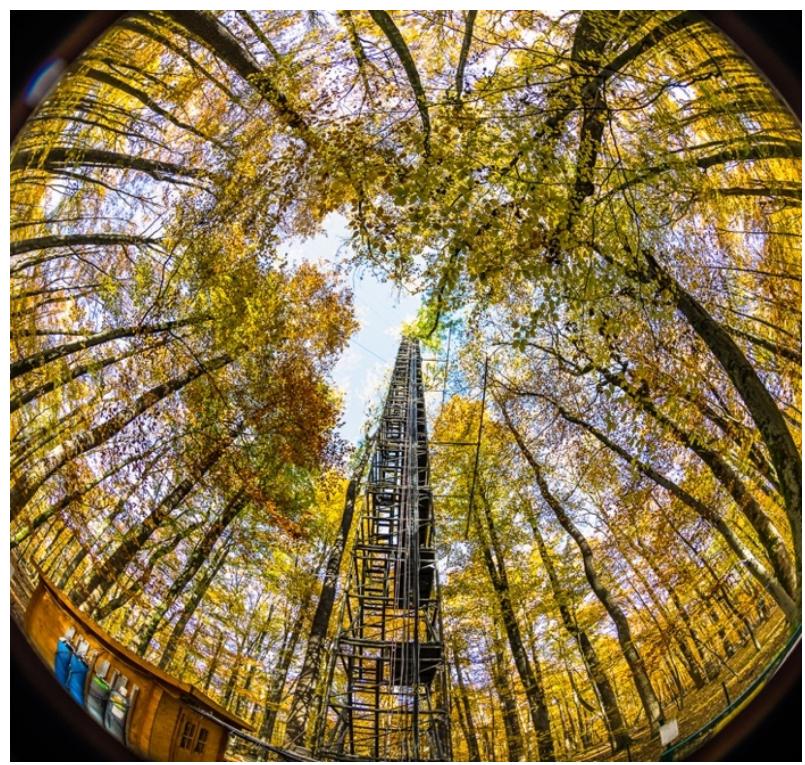

Figure 1: Flux tower installation in the Hainich national park area photographed in November 2018 from the forest ground level (fisheye).

\section{METHODS AND RESULTS}

\subsection{UAV Data Pre-Processing}

SfM (Structure from Motion) methods for data processing to georeferenced dense point clouds, digital surface model and ortho image mosaic level were used in an Agisoft Metashape cluster environment (www.agisoft.com, Agisoft LLC, St.Petersburg, Russia). Description of the Agisoft Metashape workflow can be found e.g. in Turner, Lucieer and Wallace (2014) or in Dandois and Ellis (2013). Agisoft implements digital photogrammetry techniques together with computer vision methods. 


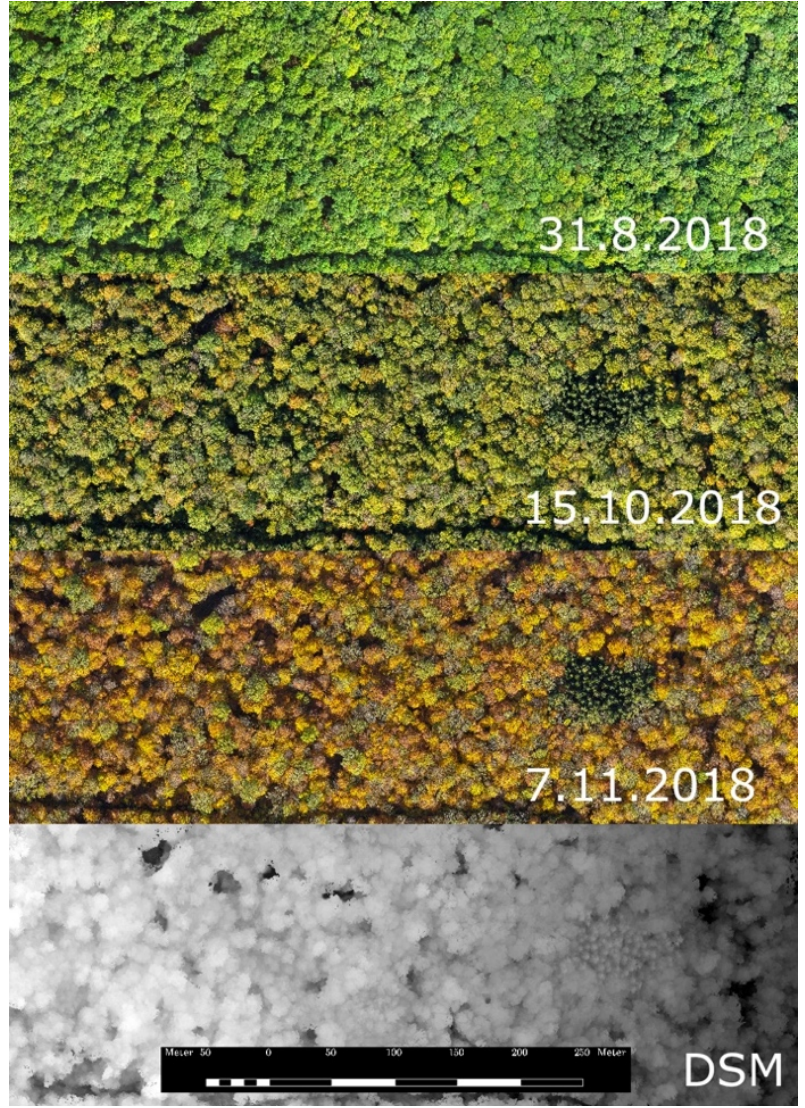

Figure 2: Subset of the study area with RGB spectral properties (uncalibrated) from 31.8., 15.10. and 7.11.2018 and digital surface model (DSM) below.

After initial feature matching an iterative bundle adjustment is applied and positions of the cameras and the $3 \mathrm{D}$ positions of the features are measured.

The August dataset was spatially corrected using DGPS (Stonex GNSS) measured reference GCPs. These GCPs were measured on highly reflective ground targets and later found in the relevant images and integrated into the Agisoft workflow as reference points. The October and November data mosaics were geometrically co-registered to the August reference dataset. Agisoft data processing was done using the full resolution image files for initial image alignment and dense point cloud matching (compare with the processing configuration in Table 2). All three dataset types - the SfM acquired point clouds, the digital surface model (DSM) and the ortho mosaic were exported to standard file formats (LAZ - compressed LAS format and PCIDSK 16 bit raster format) (Table 3 and Figure 2).

The point cloud model from August was used for the morphological crown analysis, the multitemporal dataset from August, October and November was used together for crown based spectral and textural feature analysis.

A Digital Canopy height Model (DCM) was produced applying simple terrain model subtraction. The digital terrain model (DTM) was calculated based on local minima mapping in $120 \mathrm{~m}$ search distance of the point cloud model. The point cloud model was exported to LAZ format including colour information and height-based ground/vegetation surface classification information. Reference data for 50 tree crowns was provided by the Hainich national park administration and extended visually to 100 tree crowns in the dataset, partly using the Huss-area reference information from 2013 (Figure 5) from Huss and Manning (2016).

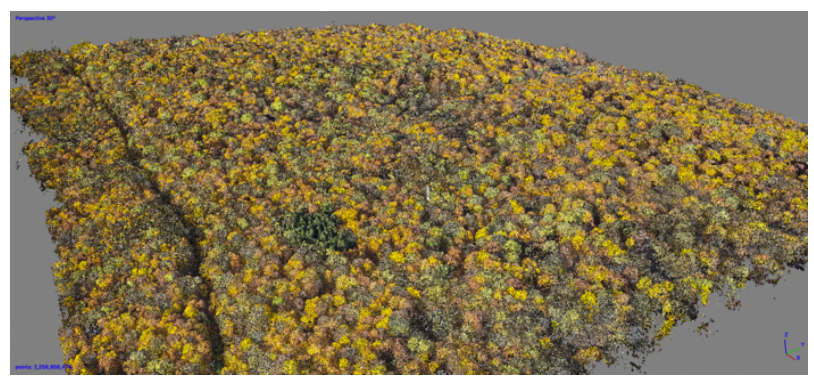

Figure 3: Perspective view of the dense point cloud model (full resolution point cloud with 2.23 billion points on approx.

100 ha) with attributed ortho mosaic RGB values. Hainich national park (partly showing the "Huss area").

\begin{tabular}{|l|c|c|}
\hline Python Task & \multicolumn{2}{|c|}{ Metashape Processing Parameter } \\
\hline $\begin{array}{l}\text { Chunk.match } \\
\text { photos }\end{array}$ & Accuracy: & $\begin{array}{c}\text { High (full resolution } \\
\text { image files) }\end{array}$ \\
\cline { 2 - 3 } $\begin{array}{l}\text { Chunk.align } \\
\text { cameras () }\end{array}$ & $\begin{array}{c}\text { Generic/Reference } \\
\text { preselection: }\end{array}$ & yes/yes \\
\cline { 2 - 3 } & Key point limit: & 0 (no limit) \\
\cline { 2 - 3 } & Tie point limit: & 4000 \\
\cline { 2 - 3 } & $\begin{array}{c}\text { Adaptive camera } \\
\text { model fitting: }\end{array}$ & yes \\
\hline $\begin{array}{l}\text { Chunk.build } \\
\text { Depthmaps / } \\
\text { chunk.build } \\
\text { densecloud () }\end{array}$ & Quality: & $\begin{array}{c}\text { "Ultra quality" (full } \\
\text { resolution files) }\end{array}$ \\
\cline { 2 - 3 } & Filtering & $\begin{array}{c}\text { Disabled (no point } \\
\text { filtering) }\end{array}$ \\
\cline { 2 - 3 } $\begin{array}{l}\text { Chunk.build } \\
\text { dem / } \\
\text { chunk.build } \\
\text { orthomosaic() }\end{array}$ & Point color & yes \\
\cline { 2 - 3 } Tweaks & Enable hole filling & Mosaic \\
\cline { 2 - 3 } & Coordinate system & WGS84/UTM32N \\
\hline
\end{tabular}

Table 2. Agisoft Metashape 1.5.1. cluster processing setup for the sub processes "Align Photos", "Build Dense Cloud", "Build DEM", "Build Ortho Mosaic".

\begin{tabular}{|l|c|}
\hline \multicolumn{1}{|c|}{ Datasets } & Dataset Specifications \\
\hline Ortho Mosaic & $\begin{array}{l}\text { Spatial resolution: 3 cm, WGS84 } \\
\text { UTM32, Bayer RGB, 7 DGPS GCPs } \\
\text { RMSE: } 11,5 \mathrm{~cm} \text {. Okt./Nov. data is } \\
\text { polynomial co-registered to the } \\
\text { August ortho mosaic. }\end{array}$ \\
\hline $\begin{array}{l}\text { DSM /DTM and } \\
\text { derived nDSHM }\end{array}$ & $\begin{array}{c}\text { Spatial resolution: } 3 \mathrm{~cm} \text { (32R), } \\
\text { UTM32N, WGS84 }\end{array}$ \\
\hline $\begin{array}{l}\text { Point cloud model } \\
\text { full/medium/low } \\
\text { resolution, low res. } \\
\text { ground points } \\
\text { classified using 120 } \\
\text { m regional local min } \\
\text { filtering }\end{array}$ & $\begin{array}{c}\text { Full: } 2.600000000 \text { points on 100 ha } \\
=26 \text { mio/ha (approx. 2600 } \\
\text { points/m²) }\end{array}$ \\
& $\begin{array}{c}\text { Medium: } 273 \text { million points } \\
\text { cow: } 16 \text { million points (laz file } \\
\text { format, CloudCompare binary } \\
\text { entities format), WGS84 UTM32N. }\end{array}$ \\
\hline
\end{tabular}

Table 3: UAV based georeferenced datasets processed from 612/625 images using Agisoft Metashape. 


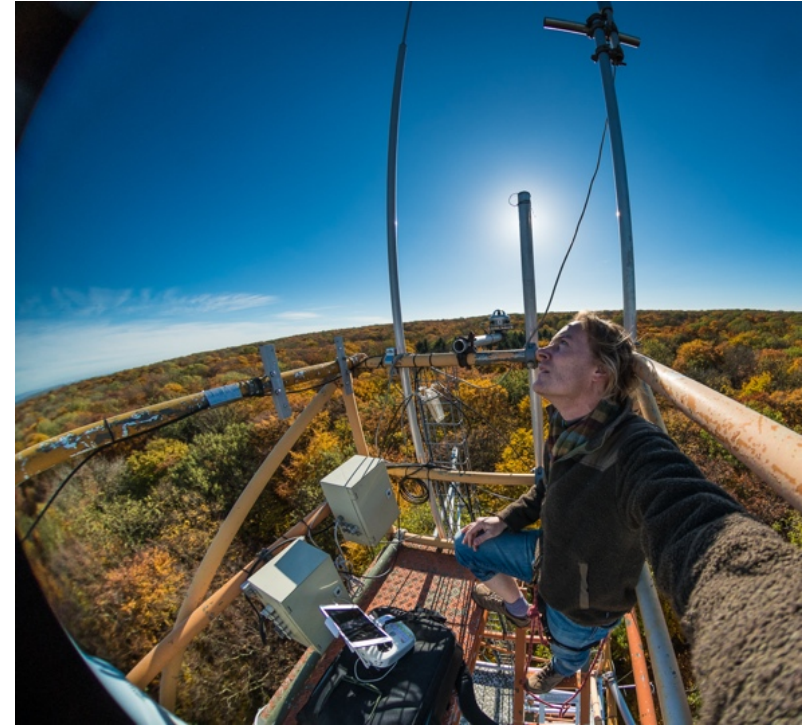

Figure 4: UAV start from the flux tower platform $40 \mathrm{~m}$ above ground level in the Hainich national park.

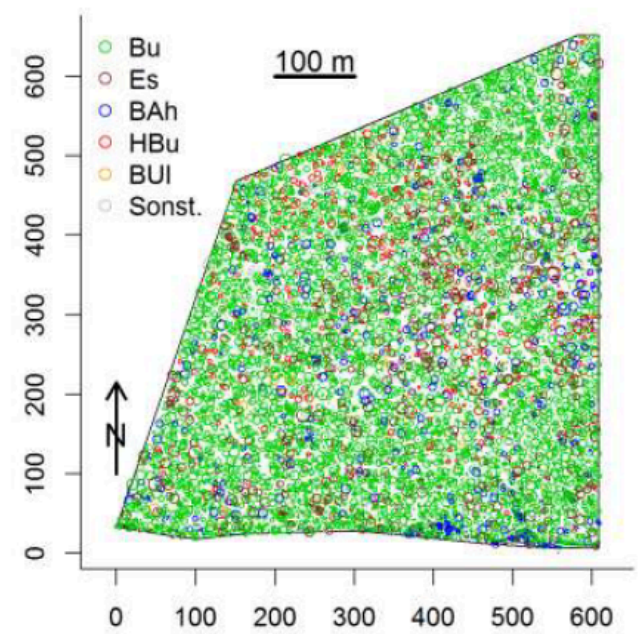

Figure 5: "Huss"-area (defined in summer 1999 by J. Huss and Smaltschinski - University of Freiburg) and individual tree crown reference information in the Hainich national park

(status 2013). The main tree species (Bu/Es/BAh) (Nationalparkverwaltung Hainich, 2016. Exkursionsführer Wissenschaft im Hainich, Hainich-Tagung 27-29.4.2016 Bad Langensalza, PDF download).

\subsection{High Resolution Point Cloud and Multi-temporal Image Band Ratio Features}

Image object and point cloud feature analysis was started after initial object-based shadow masking and ortho image subsegmentation into $6.25 \mathrm{~m}^{2}$ crown objects.

The nine spectral channels (uncalibrated RGB information from all flight campaigns) were used to calculate a multitemporal shadow mask based on mean brightness value thresholds in every month for image objects larger 0.1 ha. The shadow mask defined gaps in the stand structure and was later excluded from further tree species crown analysis. The remaining crown surface area was re-segmented into a grid cell system of $2.5 \times 2.5 \mathrm{~m}^{2}$. Reference tree crown objects for each species were selected using data from the national park administration and extended with data from the Huss-area and by manual delineation of additional trees for the class "dead trees". For these objects we analysed different spectral and image-morphological as well as height-variance specific features, point cloud height variance and surface roughness features. The following features (Table 4) were zonally calculated for the dominating tree species: 1. beech (Fagus sylvatica - BU), 2. ash (Fraxinus excelsior - ES)) and 3. sycamore maple (Acer pseudoplatanus - BAH), 4. hornbeam (Carpinus betulus - HBU), 5. dead tree crowns (Dead) and 6. early November defoliated tree crowns (mainly ash) - DF). Other tree species are field maple, wych elm (Ulmus Glabra), lime trees, Norway maple, cherry and oak trees.

\begin{tabular}{|c|c|}
\hline Feature type & Description \\
\hline Stdev (SD) object RGB & $\begin{array}{l}\text { Stdev (SD) from 8Bit } \\
\text { uncalibrated DN (RGB) }\end{array}$ \\
\hline Mean object RGB DN & 8Bit uncalibrated DN \\
\hline $\begin{array}{l}\text { Haralick texture measures: } \\
\text { Homogeneity \& Angular } \\
\text { Second Moment (Ortho } \\
\text { mosaic) }\end{array}$ & $\begin{array}{c}\text { Omni directional and in } 0^{\circ} \text {, } \\
45^{\circ}, 90^{\circ} \text { and } 135^{\circ} \text { (object } \\
\text { based) }\end{array}$ \\
\hline $\begin{array}{l}\text { Normalized Difference } \\
\text { Green-Red Index (ortho } \\
\text { mosaic) (NDGRI). }\end{array}$ & $N D G R I=\frac{(G r-R e)}{(G r+R e)}$ \\
\hline \multicolumn{2}{|c|}{$\begin{array}{l}\text { Multi Temporal Green Red Index Difference (MTGRID), } \\
\text { three point convex-concave autumn coloration index (-1 to } \\
\text { 1). } \\
\qquad M T G R I D=\frac{\left(N D G R I_{\text {aug }}+N D G R I_{\text {nov }}\right)}{2}-N D G R I_{\text {oct }}\end{array}$} \\
\hline $\begin{array}{l}\text { Local gaussian surface } \\
\text { curvature per point in } 1,2 \\
\text { and } 6 \mathrm{~m} \text { radius neighbour- } \\
\text { hood), resampled point cloud } \\
\text { to } 16 \text { mio. points, SD. }\end{array}$ & $\begin{array}{l}\mathrm{K} \text { based on a sphere } \\
\text { surface, } \mathrm{K}=1 / \mathrm{r}_{1} * 1 / \mathrm{r}_{2}= \\
1 / \mathrm{r}^{2}, \text { inverted, unsigned, } \\
\text { calculated from quadric } \\
\quad \text { function fitting. }\end{array}$ \\
\hline $\begin{array}{l}\text { Surface roughness (in a re- } \\
\text { sampled point cloud) }\end{array}$ & $\begin{array}{l}\text { Point distance to the plane } \\
\text { of neighbourhood points. }\end{array}$ \\
\hline Point density (number/area) & Points per $\mathrm{m}^{2}$ \\
\hline $\begin{array}{l}\text { Point height variability ( } 240 \\
\text { million / } 2260 \text { million) SD. }\end{array}$ & $\begin{array}{c}\text { Height SD in } 2.5 \times 2.5 \mathrm{~m} \\
\text { zones. }\end{array}$ \\
\hline
\end{tabular}

Table 4: Spectral, point height and surface shape-based feature descriptions of the Hainich forest area for reference tree

\subsection{Results} species plots.

Spectral separability analysis was calculated for the $6.25 \mathrm{~m}^{2}$ sized image objects with J-M separability - (Jeffries-Matusita Distance - Bruzzone et al. 2005). The Normalized Difference Green-Red Index (NDGRI) (Table 4) (2) also named GRND (Green-Red Normalised Difference) (Tucker 1979, Hunt et al. 2015) showed best separability results with the November data (Table 5). The spectral data from November clearly differentiated ES, BU and HBU and to a certain degree also $\mathrm{BAH}$. This was expected since the timing of the reflectance change in autumn is very much tree species specific. Dead and November-defoliated crowns clearly are distinguishable using the full NDGRI series (Figure 6). Point density and point cloud height variability (standard deviation) did not differentiate the different crown species types in August (compare with Figure 7). Multitemporal point cloud height analysis however indicated that late autumn tree crown point clouds show the starting defoliation with increased point height variability with some deciduous tree species types. 


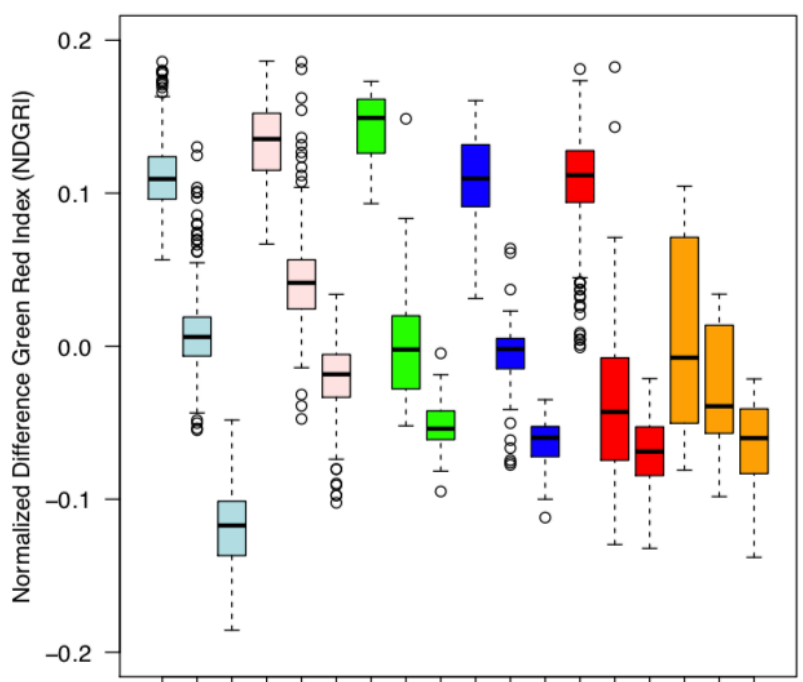

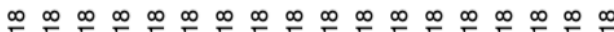

$\infty$ 으

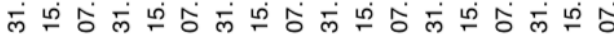

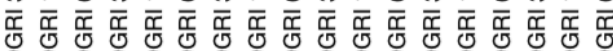

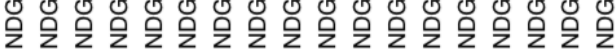

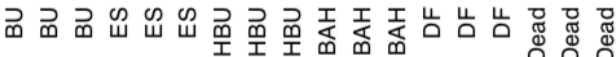

Figure 6: Normalized Difference Green-Red Index values for August, October and November RGB data of the dominating tree species (beech (BU), ash (ES), maple (BAH), hornbeam (HBU) and November-defoliated (DF)/ dead crown class.

\begin{tabular}{|c|c|c|c|c|c|}
\hline J-M & HBU & BAH & ES & DF & DEAD \\
\hline \multirow{3}{*}{ BU } & 1,37 & 1,20 & 1,72 & 0,82 & 0,84 \\
\hline & 0,16 & 0,08 & 0,37 & 0,50 & 0,35 \\
\hline & 0,47 & 0,04 & 0,21 & 0,07 & 1,15 \\
\hline \multirow{3}{*}{ HBU } & \multirow{3}{*}{-} & 0,12 & 0,42 & 0,18 & 0,12 \\
\hline & & 0,14 & 0,32 & 0,20 & 0,11 \\
\hline & & 0,45 & 0,05 & 0,43 & 1,44 \\
\hline \multirow{3}{*}{ BAH } & \multirow{3}{*}{ - } & \multirow{3}{*}{ - } & $\mathbf{0 , 8 3}$ & 0,08 & 0,12 \\
\hline & & & 0,61 & 0,21 & 0,16 \\
\hline & & & 0,05 & 0,00 & 0,99 \\
\hline \multirow{3}{*}{ ES } & \multirow{3}{*}{-} & & \multirow{3}{*}{ - } & 0,79 & 0,58 \\
\hline & & & & 0,91 & 0,76 \\
\hline & & & & 0,21 & 1,32 \\
\hline \multirow{3}{*}{ DF } & \multirow{3}{*}{ - } & \multirow{3}{*}{ - } & \multirow{3}{*}{ - } & \multirow{3}{*}{ - } & 0,02 \\
\hline & & & & & 0,03 \\
\hline & & & & & 0,94 \\
\hline
\end{tabular}

Table 5: Separability analysis (Jeffries-Matusita Distance) for the main tree species (Normalized Difference Green-Red Index for November (above), October(mid) and August (below) 2018 data).

Results from the multi temporal point cloud analysis are not included in this paper but will be published at a later stage of this project.

\subsubsection{Point cloud height variability}

Results from the August point cloud height variability analysis indicate a higher variability for HBU compared to other tree species. Exceedingly high variability with August defoliated crowns (Figure 7) is expected. Point density per sqm however is difficult to attribute to different vegetation types and vegetation densities. Variability in the medium resolution point cloud model (273 million points) is between 100 and 800 points per sqm but variability clearly overlaps for the different main tree species (Figure 7) and can also be attributed to illumination condition changes variability of feature density and variations in image overlap (image overlap
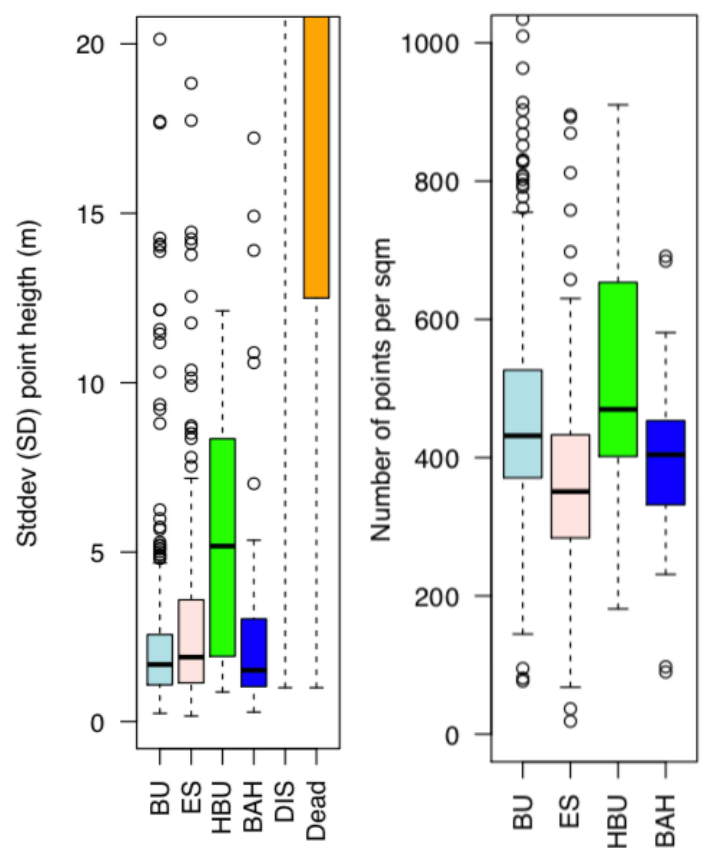

Figure 7: Variability of the point cloud height information sampled over $2.5 \times 2.5 \mathrm{~m}^{2}$ plots for the dominating tree species (beech (BU), ash (ES), maple (BAH), hornbeam (HBU) and defoliated / dead tree classes.

for this project was however kept constant at $74 \%$ along track and $74 \%$ across track).

Point density is therefore a weak spatial feature for this kind of analysis and also shows multi modal distributions.

\subsubsection{Local gaussian surface curvature}

For this analysis we also investigated gaussian surface curvature $\mathrm{K}$ and surface roughness descriptions calculated for different point cloud neighbourhood distances (radiuses of the neighbourhood). Gaussian curvature is usually calculated as a product of $\mathrm{k} 1$ and $\mathrm{k} 2(\mathrm{~K}=\mathrm{k} 1 * \mathrm{k} 2)$. The mean curvature is calculated as $\mathrm{H}=1 / 2 *(\mathrm{k} 1+\mathrm{k} 2)$. Gaussian curvature can be either negative (hyperbolic surface) or positive (elliptic surface). In our study we used an implementation with $\mathrm{k} 1$ and $\mathrm{k} 2$ identical in a concept with a computed radius from a best fitting of a quadric to the neighbourhood points $\left(\mathrm{K}=1 / \mathrm{r}_{1}\right.$ * $\left.1 / \mathrm{r}_{2}\right)$.

Low neighbourhood distance calculations create a stronger variability between different surface curvatures on a surface. This can be explained with the smaller neighbourhood kernel that can also describe stronger curvature values (smaller sphere radiuses) but can also be influenced by noise. Very large neighbourhood spheres likely will even-out small local surface height variabilities and noise and will generally also create smaller curvature radius values. Since the gaussian surface calculation for very dense point clouds with larger radius definitions is computational very expensive we reduced the surface density to a thinned point cloud with 16 million points (random thinning to 1 point per $10 \times 10 \mathrm{~cm}^{2}$ ). We measured curvature for a $1 \mathrm{~m}, 2 \mathrm{~m}$ and $6 \mathrm{~m}$ sphere radius for every point for all deciduous tree species training areas (Figure 8-9). Surface curvature variability was measured using "Standard Deviation" (SD) of the curvature within every $2.5 \mathrm{x}$ $2.5 \mathrm{~m}^{2}$ tree crown reference plot area. The resulting SD is provided in Figure 8 and 9. Boxplots show information about the data distribution with indicated median, upper and lower quantile and maximum/minimum of the data distribution (for 
values within the 1.5 factor limit of the inter-quartile distance) - values outside this range are shown as outliers. Since the measured values of curvature are not normal-distributed the boxplot visualisation is not fully adequate here. In Figure 8 the median values are clearly shifted and various outlier clusters are visible. We also provide histograms in A1 (Appendix) that show in detail the multi modal data distribution of the point cloud curvature SD values and point cloud height SD values. A radius of 1 meter around every point indicates as expected also slightly better separability compared to $2 \mathrm{~m}$ and $6 \mathrm{~m}$ radius but the absolute variability also increased. The $6 \mathrm{~m}$ radius is clearly already detecting the full crown surface curvature and is not sensible anymore to surface roughness (figure not provided due to paper length restrictions).
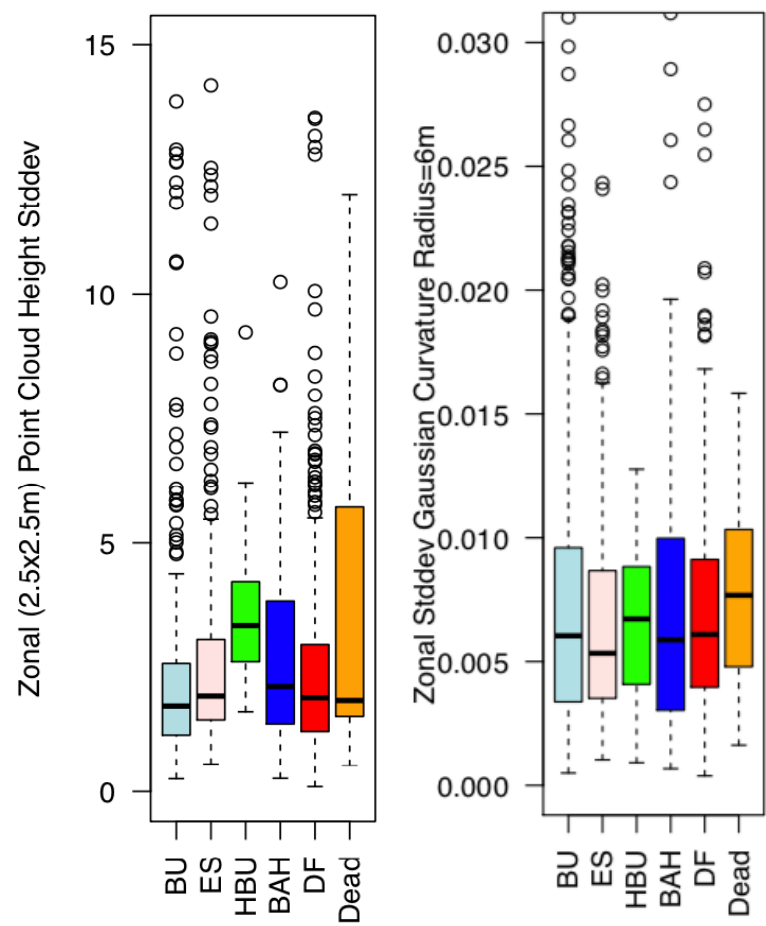

Figure 8: Local point cloud height variability SD (left) and gaussian curvature measures SD (right) investigating a radius of $\mathrm{r}=6 \mathrm{~m}$ neighbourhood sphere. Values in $1 / \mathrm{r}$ (radius) using quadratic fitting method. Zonal curvature variability (SD)

calculated on $2.5 \mathrm{~m} \times 2.5 \mathrm{~m}$ crown surface regions.

The position of the training areas relative to the crown surface border is critical for crown surface shape parameterisations. Gaussian surface curvature also is best calculated on continuous surface types. SfM derived tree crown point clouds usually show a three-dimensional character with penetration into the crown surface. We did not account for this variability. The surface thinning was done using a random point selection. Relative position to the crown centre is also a relevant property of the point curvature value especially for the curvature values with large neighbourhood spheres. However, in Figure 9 we can demonstrate that gaussian curvature SD is clearly linked to the 3-dimensional character of the crown surface and changes with different crown species.

Curvature and height statistics were calculated on the basis of the August flight campaign point cloud and crown closure was high at this moment. The point cloud height variability for the different tree species indicates higher variability with dead and defoliated crown types (class "Dead" in Figure 8).
November defoliated tree crowns are not showing this variability since the height map comes from August.
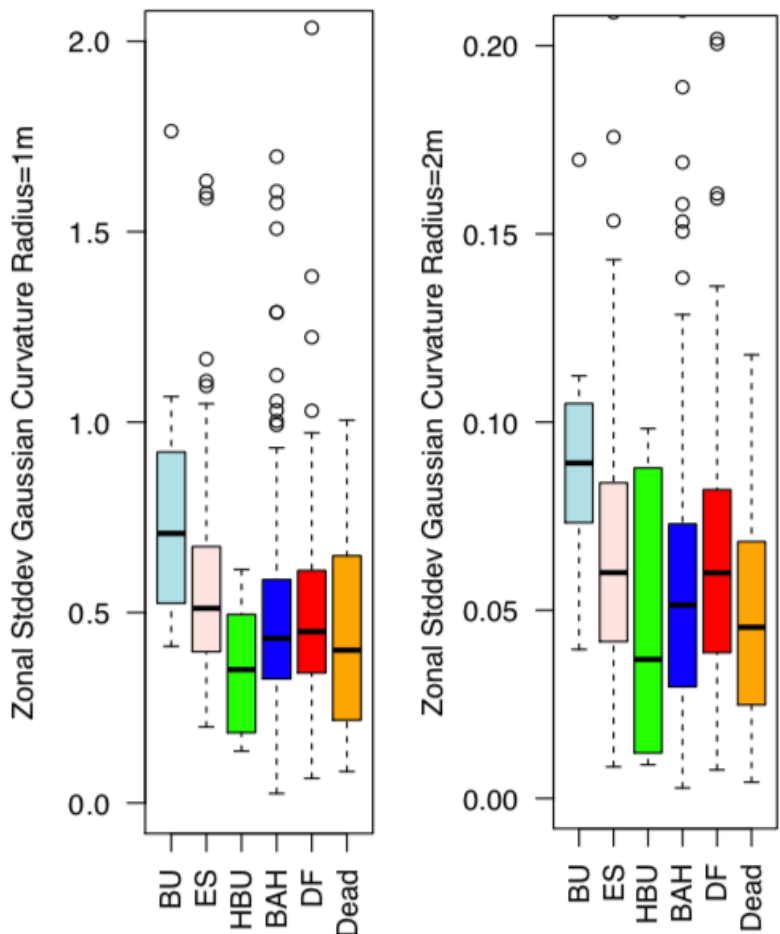

Figure 9: Local gaussian curvature measures investigating a radius $\mathrm{r}=1 \mathrm{~m}$ (left) and $\mathrm{r}=2 \mathrm{~m}$ (right) neighbourhood sphere. Values in $1 / \mathrm{r}$ (radius) using quadratic fitting method. Zonal curvature variability (SD).

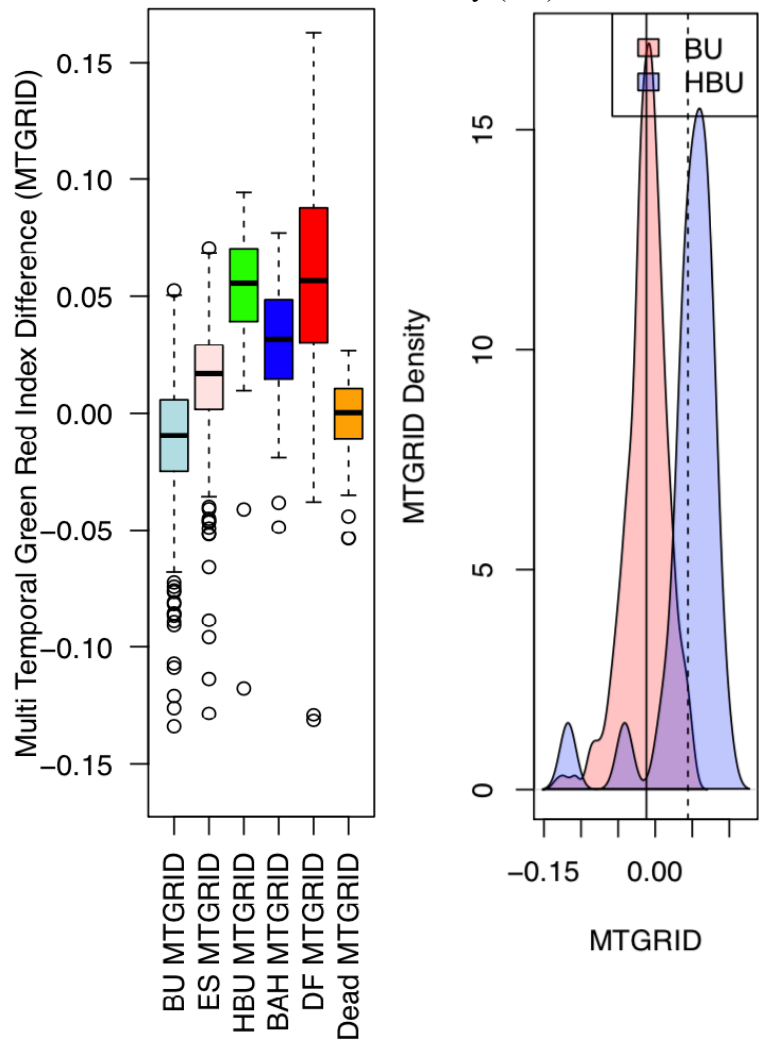

Figure 10: Multi Temporal Green Red Index Difference (MTGRID) feature for the quantification of the green-red spectral defoliation change signature (negative $=$ convex shape, positive $=$ concave shape) 
3.3.3 Multi Temporal Green Red Index Difference

We developed a Multi Temporal Green-Red Index Difference feature (MTGRID) (1) based on the NDGRI (2) to quantify species specific differences of the change in green and red reflectance in the autumn colouring period between August and November.

$$
M T G R I D=\frac{\left(N D G R I_{\text {aug }}+N D G R I_{\text {nov }}\right)}{2}-N D G R I_{\text {oct }}
$$

where $\mathrm{NDGRI}=$ normalized difference green red index

This difference index measures the amount of deviation of the October spectral response measured with a normalized Difference Green Red Index (NDGRI):

$$
\begin{aligned}
& N D G R I=\frac{(G r-R e)}{(G r+R e)} \\
& \text { where } \quad \text { Gr }=\text { green channel }
\end{aligned}
$$

from the mean of August and November - showing deviations from the expected (but not necessarily true) linear trend between August and November given that the time difference is identical and spectral change is linear with time. Negative values describe a convex progression from August to November whereas positive values indicate a concave change. This difference index is based on ratio indices and therefore creates transferrable and robust result - however the temporal dimension is critical for a comparison with other data sets and MTGRID should be calibrated for non-equal acquisition intervals with a dedicated weighting coefficient if used for comparisons. Results (Figure 10) indicate a good separability of the different main tree species using MTGRID.

\section{SUMMARY \& CONCLUSIONS}

This study demonstrates that multi seasonal (late-August, midOctober, early-November) RGB data from Bayer-sensors with limited spectral resolution and very high-resolution point cloud height information from low flying UAV-systems can be used to extract fine scale information to differentiate deciduous tree species types. We found multi-seasonal spectral data dimensionality compressed to a multi temporal difference ratio (MTGRID) to be sufficient to differentiate 4-6 deciduous tree crown types. Spectral data from three flight campaigns was converted to a normalized difference multi seasonal green-red ratio. Additionally, local crown surface roughness was parametrized using a local roughness and a local gaussian curvature descriptor in three search distances. These features are promising for multi seasonal forest stand surface shape description that could potentially also characterise the progression of defoliation in late autumn. This study was computing hardware limited since derived 3Dfeatures for very large 3D point clouds for a full forest stand region are computational expensive to process. We therefore reduced the point cloud density for the gaussian surface curvature analysis and for roughness calculations from 2.2 billion points to 16 million points. This clearly limited the potential roughness parametrisation. So far, we did not integrate multi seasonal point cloud analysis but change of surface properties due to defoliation are likely powerful features. Summer 2018 was an exceptional warm and dry summer in Germany and defoliation started much earlier than in previous years. Results of the multi temporal analysis are likely not transferrable to other years - even given the same acquisition times are used. More reference data will be included in this study to differentiate more crown species types in 2019. More work is also planned with morphological crown features from leaf-off data captured March 2019.

\section{ACKNOWLEDGEMENTS}

Very much acknowledged is the support of the Hainich National Park Administration for this project. We also wish to thank A. Knohl, Chair for Bioclimatology, University of Göttingen for the supportive cooperation and admission to the Hainich flux tower installation and Frank Tiedemann for the technical support climbing the tower various times. Parts of this work used technical equipment financed by the EFRE (European fond for regional development) for the TerraSensE project (Terrestrial Sensors for high resolution spatial analysis of land surface processes). Acknowledged is also the access to the Friedrich-Schiller-University HPC cluster ARA with Nvidia TESLA V100 GPU installations. This work and extensions related to this work will also be presented partially on http://www.jenacopterlabs.de.

\section{REFERENCES}

Bay, H.; Ess, A.; Tuytelaars, T.; van Gool, L., 2008. SURF: Speeded up robust features. CVIU 2008, 110, 346-359.

Brandtberg, T., 2007. Classifying individual tree species under leaf-off and leaf-on conditions using airborne lidar. ISPRS Journal of Photogrammetry and Remote Sensing 61, 325-340.

Bruzzone, L., F. Roli, S.B. Serpico, 1995. An extension to multiclass cases of the Jefferys-Matusita distance. IEEE Transactions on Pattern Analysis and Machine Intelligence 33:1318-1321.

Carrivick, J.L., Smith, M.W. \& D.J. Quincey., 2016. Structure from Motion in the Geosciences. John Wiley \& Sons, Ltd., West Sussex, UK.

Colomina, I., Molina, P., 2014. Unmanned aerial systems for photogrammetry and remote sensing: A review. ISPRS Journal of Photogrammetry and Remote Sensing, Vol. 92, June 2014, p79-97.

Dandois, J.P., Ellis, E.C., 2013. High spatial resolution 3dimensional mapping of vegetation spectral dynamics using computer vision, Remote Sens. Environ. 2013, 136, 259-276.

Hirschmugl, M., M. Ofner, J. Raggam, M. Schardt, 2007. Single tree detection in very high-resolution remote sensing data, Remote Sens. Environ., 110 (2007), pp. 533-544.

Hollaus, M., Mücke, W., Höfle, B., Dorigo, W., Pfeifer, N., Wagner, W., Bauerhansl, C., Regner, B., 2009. Tree species classification based on full-waveform airborne laser scanning data. In: Popescu, S., Nelson, R., Thao, K., Neuemschwander, A. (Eds.), Silvilaser 2009. 14-16 October 2009, College Station, USA, pp. 54-62.

Hunt, E. R., Cavigelli, M., Daughtry, C. S. T., McMurtrey, J. E., and C. L. Walthall, 2005. Evaluation of Digital Photography from Model Aircraft for Remote Sensing of Crop Biomass and Nitrogen Status, Precision Agriculture, 6:359378. 
Huss, J., Manning, D.B., 2006. Entwicklungsdynamimik eines buchendominierten Naturwald Dauerbeobachtungsbestandes auf Kalk im Nationalpark Hainich Thüringen, Waldökologie online, Heft 3, 67-81, Freising, Deutschland 2006.

Kim, S., McGaughey, R.J., Andersen, H.E., Schreuder, G., 2009. Tree species differentiation using intensity data derived from leaf-on and leaf-off airborne laser scanner data. Remote Sensing of Environment 113, 1575-1586.

Korpela, I., Ørka, H.O., Maltamo, M., Tokola, T., Hyyppä, J., 2010. Tree Species Classification Using Airborne LiDAR Effects of Stand and Tree Parameters, Downsizing of Training Set, Intensity Normalization, and Sensor Type. Silva Fennica 44 (2), 319-339.

Lingua, A., Marenchino, D., Nex, F., 2009. Performance analysis of the SIFT operator for automatic feature extraction and matching in photogrammetric applications. Sensors, 2009, 9, 3745-3766.

Lowe, D.G., 1999. Object Recognition from Local ScaleInvariant Features. Proc. of the International Conference on Computer Vision, Corfu (Sept. 1999).

Lowe, D., 2004. Distinctive image features from scaleinvariant keypoints. Int. J. Comput. Vis., 2004, 60, 91-110.

Mlambo, R.; Woodhouse, I. H.; Gerard, F., Anderson, K., 2017. Structure from Motion (SfM) Photogrammetry with Drone Data: A Low-Cost Method for Monitoring Greenhouse Gas Emissions from Forests in Developing Countries, Forests, no. 3: 68, 2017.

Ofner, M., M. Hirschmugl, H. Raggam, M. Schardt, 2006. 3D stereo mapping by means of UltracamD data. T. Koukal, W. Schieder (Eds.), Proceedings of the International Workshop on 3D Remote Sensing in Forestry (2006) Vienna, Austria.

Ørka, H.O., Næsset, E., Bollandsas, O.M., 2009. Classifying species of individual trees by intensity and structure features derived from airborne laser scanner data. Remote Sensing of Environment 113 (6), 1163-1174.

Othmani, A., Voon, L.F.C.L., Stolz, C., Piboule, A., 2013. Single tree species classification from Terrestrial Laser Scanning data for forest inventory, Pattern Recognition Letters 34 (2013) 2144-2150.

Othmani, A., Piboule, A., Krebs, M., Stolz, C., Lew Yan Voon, L., 2011. Towards automated and operational forest inventories with T-LiDAR. SilviLaser 2011.

Persson, Å., Holmgren, J., Södermann, U., Olsson, H., 2004. Tree species classification of individual trees in Sweden by combining high resolution laser data with high resolution near-infrared digital images. In: Thies, M., Koch, B., Spiecker, H., Weinacker, H. (Eds.), In: Proc. of the ISPRS WG VIII/2, Laser Scanners for Forest and Landscape Assessment. IAPRS, XXXVI, Part 8/W2, pp. 204-207.

Pretzsch, H., 2014. Canopy space filling and tree crown morphology in mixed-species stands compared with monocultures, Forest Ecology and Management, Pages 251264.
Pretzsch, H., Forrester, D.I., Rötzer, T., 2015. Representation of species mixing in forest growth models. A review and perspectives, Ecological Modelling, Volume 313, Pages 276292.

Reitberger, J., Krzystek, P., Stilla, U., 2006. Analysis of full waveform LiDAR data for tree species classification. In: Förstner, W., Steffen, R. (Eds.), International Archives of Photogrammetry, Remote Sensing and Spatial Information 36(3), Photogrammetric Computer Vision. pp. 228-233.

Smith, M.W., J.L. Carrivick, D.J. Quincey, 2015. Structure from motion photogrammetry in physical geography.

Progress in Physical Geography: Earth and Environment, Vol 40 , Issue 2, pp. $247-275$.

Snavely, N., S. Seitz, R. Szeliski, 2008. Modelling the world from internet photo collections, International Journal of Computer Vision, 80 (2008), pp. 189-210.

Thiel, C., Schmullius, C., 2016. Comparison of UAV photograph-based and airborne lidar-based point clouds over forest from a forestry application perspective. International Journal of Remote Sensing, DOI: 10.1080/ 01431161.2016.1225181.

Tucker, C. J., 1979. Red and Photographic Infrared Linear Combinations for Monitoring Vegetation, Remote Sensing of Environment, 8:127-150.

Turner, D.; Lucieer, A.;Wallace, L., 2014. Direct georeferencing of ultrahigh-resolution UAV imagery. IEEE Trans. Geosci. Remote Sens. 2014, 52, 2738-2745.

Ullman, S., 1979. The interpretation of structure from motion. Proc R Soc Lond B Biol Sci. 1979, 203(1153), 405-426.

Weligepolage, K., Gieske, A.S.M., Su, Z., 2012. Surface roughness analysis of a conifer forest canopy with airborne and terrestrial laser scanning techniques, International Journal of Applied Earth Observation and Geoinformation, 14 (2012) 192-203.

\section{APPENDIX}
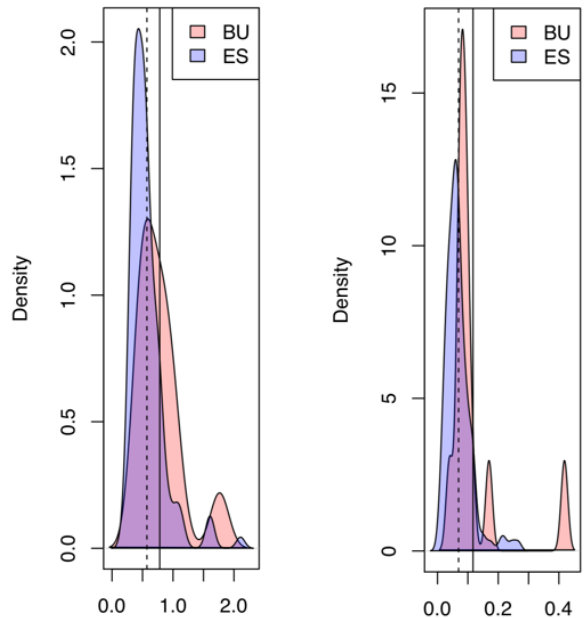

SD of Gauss. Curvature $(1 \mathrm{~m})$

SD of Gauss. Curvature $(2 \mathrm{~m})$

Figure A1: Histogramms of SD for $6.25 \mathrm{~m}^{2}$ tree crown sub regions of gaussian curvature for $1 \mathrm{~m}$ and $2 \mathrm{~m}$ neighbourhood radius (beech and ash trees). 